\title{
Modeling Landing Signal Officer Instruction Associated with Operation Guide System
}

\author{
Hui Li, Hai-tao Jiang and Xiao-dong Su \\ School of Computer and Information Engineering \\ Harbin University of Commerce \\ hrbcu_lh@163.com
}

\begin{abstract}
To ensure the operation safety of landing signal officer (LSO) to pilot during carrierbased aircraft landing, the paper proposed a "LSO-pilot-aircraft" instruction associated with operation system. LSO guide mission, and design instruction associated with operation element is been analysed. The relationship and matching of "LSO-pilotaircraft" system are exhibited by instruction associated with the operation model, and "instruction sending-operation responding-deviation correcting" process is realized based on LSO guidance instructions (original version), aircraft real-time flight states (boundary conditions) and pilot response operation (model output). Multiple loading conditions simulation results show that corrective strategies is in line with the actual situation of carrier-based aircraft landing.
\end{abstract}

Keywords: Landing Signal Officer (LSO), Introduction Associated with Operation Model, Guide System, Carrier-Based Aircraft

\section{Introduction}

To ensure landing on angled-deck of carrier safely and quickly during manual landing process, the pilot of carrier-based aircraft should be control flight path and attitude precisely. Although there are great flight characters, excellent flight control system and favorite landing approach of carrier-based aircraft, landing deviations still exist owing to complicated environment, varied disturbance and flight character loss in low-velocity status. During final approach, besides accurate manipulation of pilot, the Landing Signal Officer (LSO) should guide auxiliarily and instruct pilot by flight status at present and future. It is essential to modeling LSO for guide mission of carrier-based aircraft [1-3].

[4] Establishes LSO model for carrier-based helicopter, [5] simulates flight forecasting ability of LSO, and [6] analyses fuzzy logic during guide of LSO. Nevertheless these research have a description of LSO action, it has a little factors of consideration. To set up an exhaustive LSO guide model, this paper designs a "LSO-pilot-aircraft" instruction associated with operation system.

The rest of this paper is structured as follows: next section we first analyse LSO guide mission. Section 3 design instruction associated with operation element. The relationship and matching of "LSO-pilot-aircraft" system are exhibited by instruction associated with the operation model in Section 4. Multiple loading conditions simulation results show that corrective strategies is in line with the actual situation of carrier-based aircraft landing in Section 5. 


\section{Guide Mission Description}

The LSO landing guide mission include: at the head of final approach, LSO decides whether sending correct order or not, and in the rear, the wave-off decision making be considered. In conclusion, LSO not only supervises flight motion but also has main responsibility for landing safety during the final approach. Considering the important role of LSO, it adds the LSO landing guide and wave-off decision making system to original carrier-based aircraft landing model, the "LSOpilot-aircraft" man-machine closed loop system has been established in the end, as shown in Figure 1.

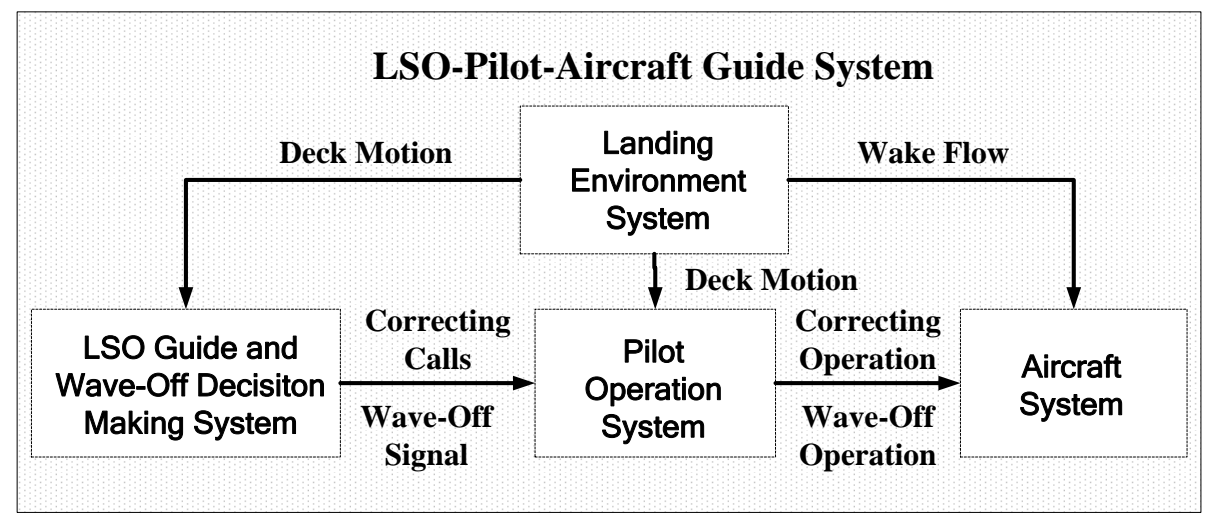

Figure 1. LSO-pilot-aircraft Guidance System

The guidance and correction of LSO is not simplicity, and the main reasons are:

1) As individual person, his guide behavior is nonlinear;

2) The control strategies rely on flight status and environment information is complex;

3) The judgment for flight status deviations and correction order are fuzziness, as "drop the nose a little" and "a little power".

Because of the nonlinear, complexity and fuzziness, it is so difficulty to establish LSO model using the traditional control technology. According to the expression form of LSO guide correction strategy, we design the guide model of LSO: "instruction sending-operation responding-deviation correcting" process is realized based on LSO guidance instructions (original version), aircraft real-time flight states (boundary conditions) and pilot response operation (model output), and it establishes the "LSO-pilot-aircraft" instruction associated with operation model finally.

\section{Instruction Associated with Operation Element}

During final approach, the practical guide process could be seen a discrete motion set including some "sending instruction (LSO)-responding-deviation operation (pilot) - flight correcting (carrier-based aircraft)" elements.

Definition 1. Instruction Associated With Operation Element (IAWOE) $h:$ In the process of landing, LSO and pilot finish one "sending instruction-respondingdeviation operation-flight correcting" status correcting course.

Definition 2. Instruction Associated With Operation Set (IAWOS) $\boldsymbol{H}=\left\{h_{k} \mid k \in K\right\}$ : For guaranteeing landing safety, LSO and pilot finish all IAWOE during one approach. 
A whole IAWOE should include three parts: LSO guide instructions, instructionreleased conditions (carrier-based aircraft flight status when instruction-releasing) and pilot responding operations (pilot maneuvering operation for the instruction).

$$
h_{k}=\left\{g_{k}, t_{k}, o_{k}\right\}, \quad g_{k} \in \boldsymbol{G}, t_{k} \in \boldsymbol{T}, o_{k} \in \boldsymbol{O}
$$

Where $\boldsymbol{G}=\left\{g_{1}, g_{2}, \ldots, g_{m}\right\}$ the set of LSO guide instructions is, $\boldsymbol{T}=\left\{t_{1}, t_{2}, \ldots, t_{m}\right\}$ is the set of instruction-released conditions, and $\boldsymbol{O}=\left\{o_{1}, o_{2}, \ldots, o_{m}\right\}$ is the set of pilot responding operations.

\subsection{Guide Instruction Set}

During emergency situations such as loss of visual landing aids, reduced cockpit visibility, excessive deck motion etc, the LSO will often be required to give pilots a complete radio talkdown, providing lineup, glideslope, and corrective information. The LSO should brief the pilots as time permits on format for the talkdown as well as expected pilot responses to calls [7-15].

Informative calls - used to inform pilots of existing situation.

Advisory calls - used to direct pilot's attention to potential difficulties and prevent possible control errors

Imperative calls-used to direct the pilot to execute a specific control action. Mandatory immediate response.

\subsection{Instruction Boundary Factors}

The information of Instruction Associated with Operation Element (IAWOE) is the flight status of carrier-based aircraft, the reference information of landing longitudinal loop, including altitude deviation $\Delta h$, velocity deviation $\Delta u$, accelerated velocity $u^{\prime}$, rate deviation of sink $\Delta v_{z}$, attitude deviation $\Delta \theta$ and range from touchdown $X$. Table 1 shows the significations of these factors.

Table 1. Instruction Boundary Factors

\begin{tabular}{l|l|l|l}
\hline$\Delta h>0$ & high & $\Delta h<0$ & low \\
\hline$\Delta u>0$ & fast & $\Delta u<0$ & slow \\
\hline$u^{\prime}>0$ & acceleration & $u^{\prime}<0$ & deceleration \\
\hline$\Delta v_{z}>0$ & climb & $\Delta v_{z}<0$ & settle \\
\hline$\Delta \theta>0$ & nose-high attitude & $\Delta \theta<0$ & nose-down attitude \\
\hline
\end{tabular}

\subsection{Response Operation of Pilot}

It should be recognized that, although the LSO can routinely command power corrections, he does not as a rule explicitly command elevator control except during a radio talk-down. Any required elevator correction will be inferred by the pilot from the nature of the LSO's call.

The integer variable "power" was introduced to represent the various levels of thrust change desired by the pilot. The variable "power" was coded in the following manner. 
Table 2. Operating Manner of Throttle

\begin{tabular}{|c|c|}
\hline POWER & Operating manner of throttle \\
\hline POWER=1 & No power call is made \\
\hline POWER=2 & A command for $\delta_{t}=1 / 6 \delta_{t \max }$ \\
\hline POWER=3 & A command for $\delta_{t}=1 / 3 \delta_{t \max }$ \\
\hline POWER $=4$ & A command for $\delta_{t}=\delta_{t \max }$ \\
\hline POWER $=5$ & $\begin{array}{l}\text { An implied command that the pilot correct a "low" condition on a night approach by applying } \\
\delta_{t}=1 / 3 \delta_{t \max } \text { until a } 1 / 4 \text { ball low is detected, at which point throttle is to be reduced to } \\
\delta_{t}=-1 / 6 \delta_{t \max } \text { until a center ball is acquired. At that point } \delta_{t}=0 \text { is to be set and held. }\end{array}$ \\
\hline POWER $=6$ & $\begin{array}{l}\text { An implied command that the pilot correct a "high" or "climbing" condition on a night } \\
\text { approach by removing } \delta_{t}=-1 / 6 \delta_{t \max } \text { until a definite settling ball is seen. At that point throttle } \\
\text { is to be advanced to } \delta_{t}=1 / 3 \delta_{t \max } \text { to arrest the rate of sink and held until the ball is stabilized. } \\
\text { Then } \delta_{t}=0 \text { is to be maintained. }\end{array}$ \\
\hline POWER=7 & The same as POWER=6 with all throttle corrections halved. \\
\hline
\end{tabular}

Associated with each approach error is an implicit requirement that the pilot interrupt his prevailing scan to check the angle-of-attack indexer and, if necessary, correct for speed errors with a feedback process around the indexer. To do this, the integer variable "scan" is used in the following manner.

Table 3. Operating Manner of Stick

\begin{tabular}{c|l}
\hline SCAN & \multicolumn{1}{c}{ Operating manner of stick } \\
\hline SCAN=1 & LSO's call conveys no implied command regarding airspeed control \\
\hline SCAN =2 & Angle-of-attack indexer is to be nulled with elevator if it is not already centered. \\
\hline SCAN =3 & $\begin{array}{l}\text { LSO call requires that a bias be placed on the indexer; via that feed-forward elevator } \\
\text { be used to establish and hold a donut and high chevron until the pilot sees a centered } \\
\text { meatball on the FLOLS. }\end{array}$ \\
\hline SCAN =4 & $\begin{array}{l}\text { Feed-forward elevator is to be used to establish and hold a donut and low chevron } \\
\text { until the pilot sees a } 1 / 2 \text { ball high state on the FLOLS. }\end{array}$ \\
\hline SCAN =5 & $\begin{array}{l}\text { The same as SCAN=4 except that the elevator corrections are to be only 1/2 as } \\
\text { large. }\end{array}$ \\
\hline
\end{tabular}

\section{LSO Instruction Associated with Operation Model}

Let $\boldsymbol{H}=\left\{h_{1}, h_{2}, \ldots, h_{k} \mid h_{k}=\left(g_{k}, t_{k}, o_{k}\right)\right\}$ be a set of instruction operations, $g_{i} \in \boldsymbol{G}=\left\{g_{1}, g_{2}, \ldots, g_{m}\right\} \quad$ be a set of LSO guide instructions, and $o_{i} \in \boldsymbol{O}=\left\{o_{1}, o_{2}, \ldots, o_{m} \mid o_{i}=\left(t_{i}, s_{i}\right)\right\}$ be a set of responsing operations of pilot, where $t_{i} \in \boldsymbol{T}=\left\{t_{1}, t_{2}, \ldots, t_{7}\right\}$ be a set of throttle operation and $s_{i} \in \boldsymbol{S}=\left\{s_{1}, s_{2}, \ldots, s_{5}\right\}$ be a set of stick operation. Let $c_{i} \in \boldsymbol{C}=\left\{c_{1}, c_{2}, \ldots, c_{m} \mid c_{i}=\left(u_{i}^{\prime}, \Delta u_{i}, \Delta \theta_{i}, \Delta h_{i}, \Delta v_{z i}, X_{i}\right)\right\}$ be a discrete set of instruction-released conditions, and where $c_{i}=\left(u_{i}^{\prime}, \Delta u_{i}, \Delta \theta_{i}, \Delta h_{i}, \Delta v_{z i}, X_{i}\right)$ is multi-set item of carrier-based aircraft flight status.

The "LSO-pilot-aircraft" instruction associated with operation model is shown as follow:

$$
\begin{gathered}
\boldsymbol{H}=\left\{h_{k}=\left(g_{k}, t_{k}, o_{k}\right) \mid k \in K\right\} \\
\text { if } c=c_{i} \in \boldsymbol{C} \text { then } g=g_{i} \in \boldsymbol{G} \\
\text { if } g=g_{i} \in \boldsymbol{G} \text { then } o=o_{i}=\left(t_{i}, s_{i}\right) \in \boldsymbol{O}
\end{gathered}
$$




$$
\begin{aligned}
c=c_{i} \in \boldsymbol{C} \Rightarrow g=g_{i} \in \boldsymbol{G} & \Rightarrow\left\{\begin{array}{l}
t=t_{i} \in \boldsymbol{T} \\
s=s_{i} \in \boldsymbol{S}
\end{array}\right. \\
& \Rightarrow o=o_{i} \in \boldsymbol{O}
\end{aligned}
$$

In the basis of expliciting LSO instruction set, Instruction boundary factors and response operation of pilot, [13] shows the rules table of of instruction associated with the operation model which is shown in Table 4, and guide correcting process is shown as Figure 2 specifically.

\begin{tabular}{|c|c|c|}
\hline Boundary situation & Verbal call & Operation \\
\hline$\Delta h<0, \quad|\Delta h|>X / 300, \quad X<1200$ & Power & $\mathrm{POWER}=3, \quad \mathrm{SCAN}=1$ \\
\hline$u^{\prime}<0, \quad X<1000, \quad\left|u^{\prime}\right| \geq 9$ & \multirow{4}{*}{ Power } & \multirow{4}{*}{ POWER $=4, \quad$ SCAN $=1$} \\
\hline$\Delta u<0, \quad X<1200, \quad|\Delta u| \geq 15$ & & \\
\hline$\Delta \theta>0, \quad X<1000, \quad|\Delta \theta| \geq 0.157 \mathrm{rad}$ & & \\
\hline$\Delta v_{z}>0,\left|\Delta v_{z}\right|>X / 150$ & & \\
\hline$\Delta \theta<0, \quad X<1000, \quad|\Delta \theta| \geq 0.052 \mathrm{rad}$ & \multirow{2}{*}{ Attitude } & \multirow{2}{*}{ POWER $=1, \quad$ SCAN $=2$} \\
\hline$\Delta u>0, \quad X<1200, \quad|u|>15$ & & \\
\hline$u^{\prime}<0, \quad X<1000, \quad 3 \leq\left|u^{\prime}\right|<6$ & \multirow{2}{*}{$\begin{array}{l}\text { You' re slow; } \\
\text { a little power }\end{array}$} & \multirow[b]{2}{*}{ POWER $=2, \quad$ SCAN $=2$} \\
\hline$\Delta u<0, \quad X<1200, \quad 5 \leq|\Delta u|<10$ & & \\
\hline$u^{\prime}<0, \quad X<1000, \quad 6 \leq\left|u^{\prime}\right|<9$ & \multirow{2}{*}{$\begin{array}{l}\text { Power; } \\
\text { You' re slow }\end{array}$} & \multirow{2}{*}{ POWER $=3, \quad$ SCAN $=2$} \\
\hline$\Delta u<0, \quad X<1200, \quad 10 \leq|\Delta u|<15$ & & \\
\hline$\Delta \theta>0, \quad X<1000, \quad 0.052 \mathrm{rad} \leq|\Delta \theta|<0.104 \mathrm{rad}$ & \multirow{2}{*}{$\begin{array}{l}\text { A little power; } \\
\text { Don' t go low }\end{array}$} & \multirow{2}{*}{ POWER $=2, \quad$ SCAN $=3$} \\
\hline$\Delta v_{z}>0, \quad X / 300 \leq\left|\Delta v_{z}\right|<R / 200$ & & \\
\hline$\Delta \theta>0, \quad X<1000, \quad 0.104 \mathrm{rad} \leq|\Delta \theta|<0.157 \mathrm{rad}$ & \multirow{2}{*}{$\begin{array}{l}\text { Power; } \\
\text { You’ re going low }\end{array}$} & \multirow{2}{*}{ POWER $=3, \quad$ SCAN $=3$} \\
\hline$\Delta v_{z}>0, \quad X / 200 \leq\left|\Delta v_{z}\right|<X / 150$ & & \\
\hline$\Delta h<0, \quad|\Delta h| \geq X / 300, \quad X \geq 1200$ & You' re low & $\mathrm{POWER}=5, \quad \mathrm{SCAN}=3$ \\
\hline$\Delta v_{z}<0, \quad\left|\Delta v_{z}\right|>X / 150, \quad X \geq 1200$ & \multirow{2}{*}{$\begin{array}{l}\text { You' re going high; } \\
\text { Ease it down }\end{array}$} & \multirow{2}{*}{ POWER $=6, \quad$ SCAN $=4$} \\
\hline$\Delta h>0, \quad X>1200, \quad|\Delta h| \geq X / 75$ & & \\
\hline$\Delta v_{z}<0, \quad\left|\Delta v_{z}\right|>X / 150, \quad X<1200$ & Fly the ball & POWER $=7, \quad$ SCAN $=5$ \\
\hline
\end{tabular}

Table 4. Rule of Instruction Associated with the Operation Model

Step 1: It should catch current flight status of carrier-based aircraft, including altitude deviation $\Delta h$, velocity deviation $\Delta u$, accelerated velocity $u^{\prime}$, rate deviation of sink $\Delta v_{z}$, attitude deviation $\Delta \theta$ and range from touchdown $X$ which compose multi-set item $y_{i}=\left(u_{i}^{\prime}, \Delta u_{i}, \Delta \theta_{i}, \Delta h_{i}, \Delta v_{z i}, X_{i}\right)$ of flight status information.

Step 2: It judges whether or not current flight status corresponds to the set of instruction-released conditions:

if $y_{i} \notin \boldsymbol{C}$ - the aircraft can flight steadily with the operation of pilot, no need to send correcting calls from LSO;

if $y_{i} \in \boldsymbol{C}$ - there are some deviation between current status and ideal one, so LSO must send correcting calls.

Step 3: It ascertain instruction information matching current flight status $y_{i} \in \boldsymbol{C}$, LSO sends "instruction associated with flight status". 
Step 4: The pilot operates "operation associated with instruction" matching LSO calls $g_{i} \in \boldsymbol{G}$, including operating of throttle $t_{i} \in \boldsymbol{T}$ and operating of stick $s_{i} \in \boldsymbol{S}$.

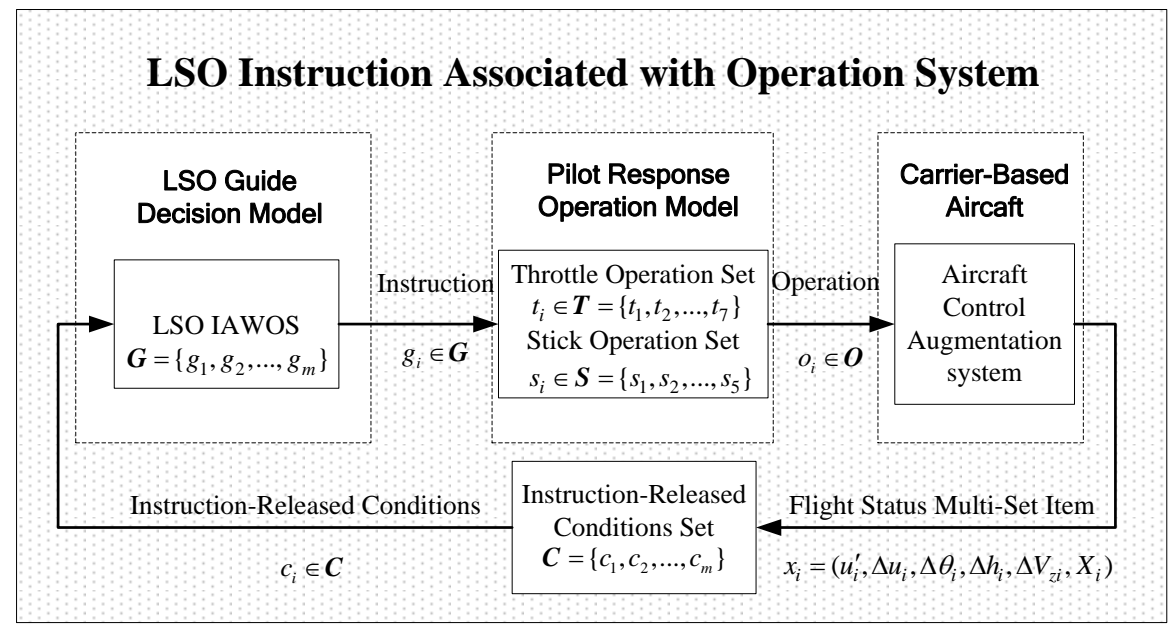

Figure 2. LSO Instruction Associated with the Operation Systems

\section{Model Verification and Analysis}

To verify the authenticity of LSO instruction associated with operation model from this paper, we can move on to some simulation for different operating conditions.

\subsection{Low Velocity Trigger "A Little Power" Instruction}

The initial range from touchdown is $926 \mathrm{~m}$, flight altitude is $36.67 \mathrm{~m}$ (glideslope deviation $-20 \mathrm{~m}$ ), initial velocity is $69.96 \mathrm{~m} / \mathrm{s}$ and angle-of-attack is $8.1^{\circ}$.

Because of longitudinal deviation, the velocity will decrease with climbing motion. It move on to simulations for no-operation situation, push stick situation and a little power situation. Figure 3 shows response curves of different velocity, angle-of-attack, height deviation and acceleration.
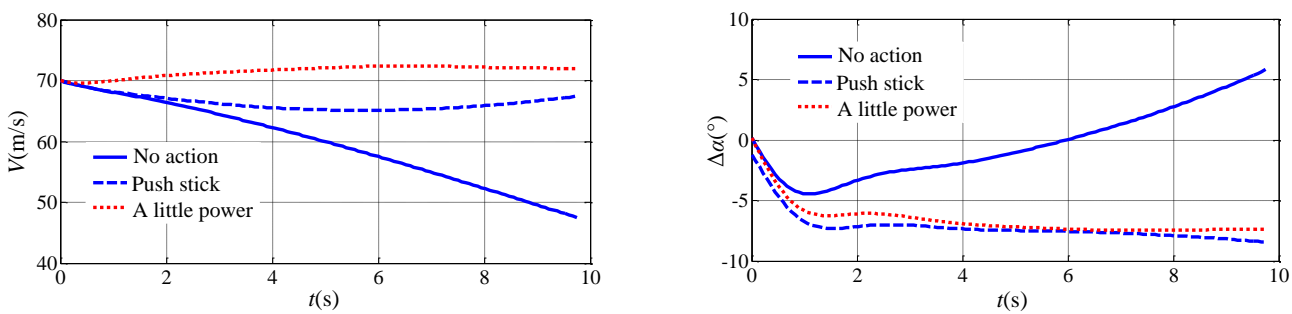

(a) Response curves of different velocity (b) Response curves of different angle-of-attack
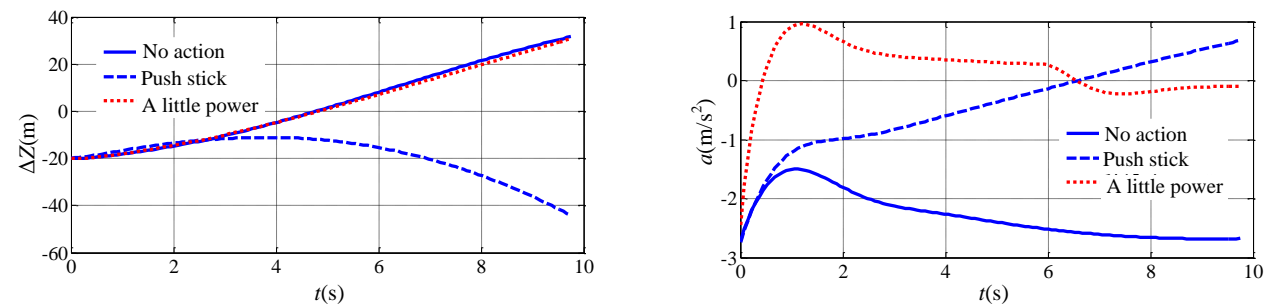

(c) Response curves of different height deviation (d) Response curves of acceleration

Figure 3. Response Curves of Different Operations 
1)When pilot executes no-operation, the velocity will decrease rapidly, cause a large deceleration, and angle-of-attack enlarges quickly after minishing a little. Aircraft will remain climbing situation of high AOA and low velocity which is so difficulty for pilot's controlling.

2)When pilot executes push-stick operation, the velocity will increase after decreasing a little, and angle-of-attack will be decrease because of pushing stick. The height deviation will be magnify during damping rapidly, and the resultant velocity increase from acceleration curves. It is adverse to landing safety with high speed and large height deviation.

3)From LSO instruction associated with operation model, we know the right call is "a little power", A command for $\delta_{t}=1 / 3 \delta_{t \max }$ and steady angle-of-attack. The velocity remains stable after a little increasing, and acceleration will be zero which can guarantee safe landing velocity range from Figure 3(a). During adjust process, angle-of-attack is decrease, altitude is increasing to compensate initial height deviation. Following every record, we can see the advantage of "a little power" instruction.

\subsection{Large Rate of Sink Trigger "Don't Go Low" Instruction}

The initial range from touchdown is $926 \mathrm{~m}$, flight altitude is $76.67 \mathrm{~m}$ (glideslope deviation $20 \mathrm{~m}$ ), initial velocity is $69.96 \mathrm{~m} / \mathrm{s}$ and angle-of-attack is $8.1^{\circ}$.

Because of longitudinal deviation, the rate of sink will increase with diving motion. It move on to simulations for no-operation situation, pull stick situation and power situation. Figure 4 shows response curves of different velocity, rate of descend, height deviation and acceleration.
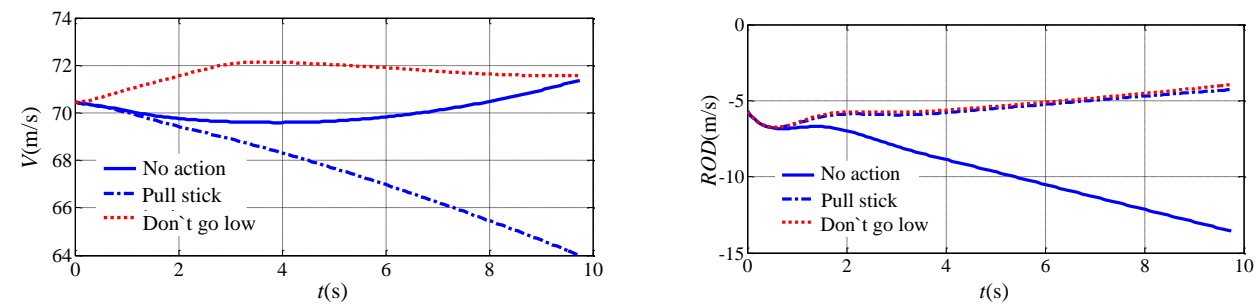

(a) Response curves of different velocity (b) Response curves of different ROD
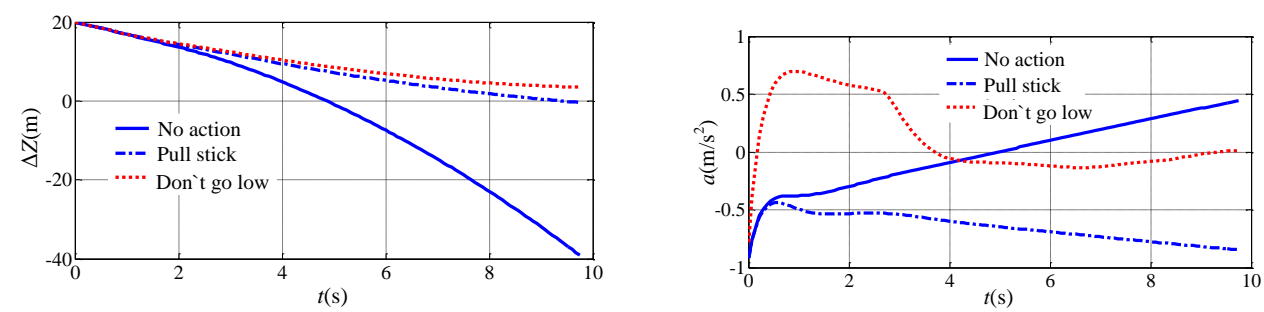

(c) Response curves of different height deviation (d) Response curves of acceleration

Figure 4. Response Curves of Different Operations

1)When pilot executes no-operation, the rate of descend will increase rapidly and height lower and lower. The height deviation from glideslope will affect ramp-strike risk.

2)When pilot executes pull-stick operation, the rate of descend will decrease gradually. Although height deviation decreases, the velocity will decrease with deceleration from velocity and acceleration curves. It is averse to landing safety with low speed. 
3)From LSO instruction associated with operation model, we know the right call is "Don't go low", A command for $\delta_{t}=1 / 3 \delta_{t \max }$ and steady angle-of-attack. The deceleration decreases stably, and the velocity will decrease after increasing a little from Figure 4(b). Acceleration will be zero which can guarantee safe landing velocity range. Following every record, we can see "Don't go low" instruction is the right one.

\subsection{Small Angle-of-pitch Trigger "Attitude" Instruction}

The initial range from touchdown is $926 \mathrm{~m}$, flight altitude is $76.67 \mathrm{~m}$ (glideslope deviation $20 \mathrm{~m}$ ), initial velocity is $69.96 \mathrm{~m} / \mathrm{s}$ and angle-of-attack is $8.1^{\circ}$.

Because of longitudinal deviation, pilot makes full use of decreasing angle-ofpitch to minish deviation. With the situation of small angle-of-pitch, it move on to simulations for no-operation situation, easy up throttle situation and pull stick situation. Figure 5 shows response curves of different velocity, rate of descend, height deviation and acceleration.
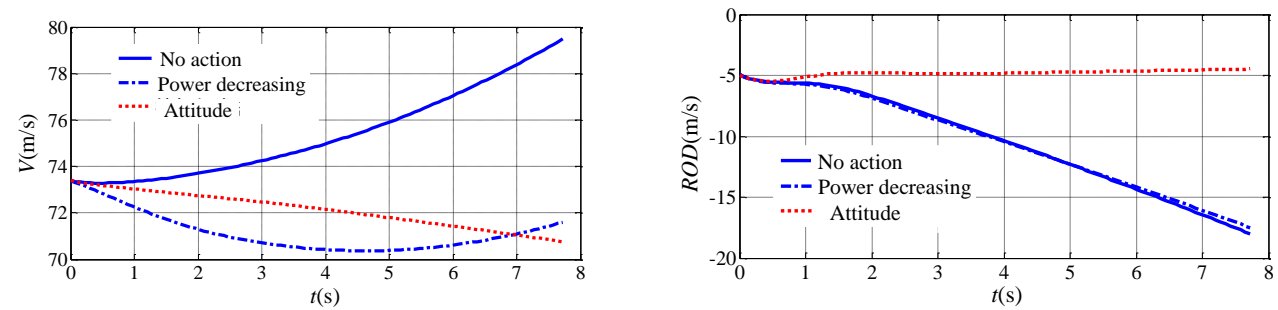

(a) Response curves of different velocity (b) Response curves of different ROD
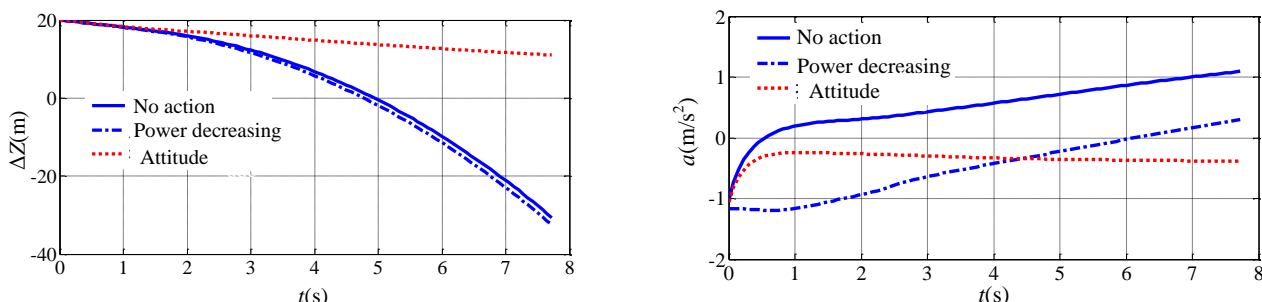

(c) Response curves of different height deviation (d) Response curves of acceleration

Figure 5. Response Curves of Different Operations

1)When pilot executes no-operation, the velocity increase significantly and continuously. The rate of descend will increase rapidly which causes height is lower and lower. The height deviation from glideslope will effect ramp-strike risk.

2)When pilot executes power decreasing, height deviation still diminish with low velocity and large acceleration. It is adverse to landing safety.

3)From LSO instruction associated with operation model, we know the right call is "Attitude", A command for steady angle-of-attack. with no change of power. The velocity will decrease and height deviation will decrease from Figure 5(a). Following every record, we can see "Attitude" instruction is the right one.

\section{Conclusion}

The difficulty of LSO guidance control is analyzed and emphasized in this paper, and LSO instruction associated with the operation model is built according to the format of LSO guidance strategy. The relationship and matching of "LSO-pilotaircraft" system are exhibited by instruction associated with the operation model, and "instruction sending-operation responding-deviation correcting" process is 
realized based on LSO guidance instructions (original version), aircraft real-time flight states (boundary conditions) and pilot response operation (model output). Multiple loading conditions simulation results show that corrective strategies is in line with the actual situation of carrier-based aircraft landing.

\section{ACKNOWLEDGEMENTS}

The author would like to thank the anonymous referees for their valuable suggestions. This work was supported by the Natural Science Foundation of Heilongjiang Province of China (Grant Nos. F201349), Science and Technology Research Foundation of Heilongjiang Education Department (Grant Nos. 12531159), the Natural Science Foundation of Heilongjiang Province of China (Grant Nos. F201423) and the Natural Science Foundation of Heilongjiang Province of China (Grant Nos. F201210).

\section{References}

[1]. R. Richards, “Artificial Intelligence Techniques for Pilot Approach Decision Aid Logic System”, Stottler Henke Associates, Inc., (2000).

[2]. T. Rudowsky, S. Cook, M. Hynes, et al., "Review of the carrier approach criteria for carrier-based aircraft", Techinical report NAWCADPAX/TR-2002/71, (2002).

[3]. R. B. Johnstone, "Development of the wave-off decision device and its relationship to the carrier approach problem", AIAA-68-846, American Inst of Aeronautics and Astronautics, Guidance, Control, and Flight Dynamics Conference, Pasadena, Calif., (1968) August 12-14.

[4]. R. Richards, J. Chrenka and M. Thordsen, "Artificial intelligence tecnique for pilot approach decision aid logic (PADAL) System", AD-A388045, (2001).

[5]. R. A. Riehards, "Application of multiple artificial intelligence techniques for an aircraft carrier landing decision support tool”, In: Proceeding of the 2002 IEEE International Conference on, vol. 1, no. 12-17, (2002), pp. 7-11.

[6]. "NAVAIR 00-80T-105", NATOPS Landing Signal Officer Manual, US, (2004).

[7]. P. G. Stueck, “LSO Pilot Interaction Simulation”, AD-765686, no. 7, (1973), pp. 16-42.

[8]. R. L. Nave, "A Pilot/LSO Simulation Conducted to Investigate Aircraft Wave-off Performance and to Determine the Ability of the Landing Signal Officer to Judge Aircraft Approaches", AD-A007515, no. 12, (1974), pp. 10-26.

[9]. R. H. Smith, "The Landng Signal Officer: a Preliminary Dynamic Model for Analyses of System Dynamics", AD-762728, no. 4, (1974) pp. 1-11.

[10].R. M. Robertson, D. W. Maxwell and C. E. Williams, "The Landing Signal Officer: Auditory Aspects", AD_A065000, no. 12, (1974), pp. 4-21.

[11].R. K. Heffley, "Outer-loop control factor for carrier aircraft”, USA, (1990), pp. 12-45.

[12].J. T. Hooks and M. E. Mcsuley, "Training Characteristics of LSO Reverse Display”, AD-A096864, no. $11,(\mathbf{1 9 8 0})$, pp. 48-62.

[13].T. B. Steven and A. B. Clyde, "Development of the Automated Performance Assessment and Remedial Training System (APARTS): a Landing Signal Officer Training Aid”, AD-A106224, no. 6, (1981), pp. 4-18.

[14].C. A. Brictson and S. T. Breidenbach, "Conceptual Development of a Preliminary LSO Carrier Lanidng Training Aid", AD-A107002, no. 9, (1981), pp. 6-14.

[15].E. M. Michael and C. C. John, "Automated Instructor Models for LSO Training System”, AD-A121177, no. 9, (1982), pp. 31-69P.

\section{Authors}

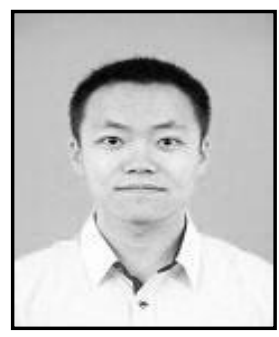

Hui Li received a D.E. degree in Control Theory and Control Engineering from Harbin Engineering University, Harbin, China, 2013. He is the member of council of the Operations Research Society of China. His recent research interests are in intelligent control, Multi-attribute decision making, fuzzy decision making. 


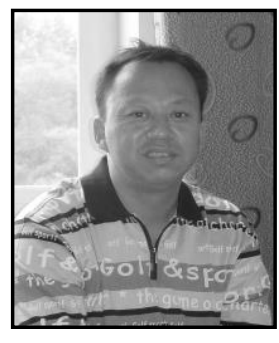

Hai-tao Jiang is an associate professor of Harbin University of Commerce. He received a M.E. degree in Software Engineering from Beijing University of Posts and Telecommunications, Beijing, China, 2010. His recent research interests are in intelligent control, digital signal processing and embedded technology.

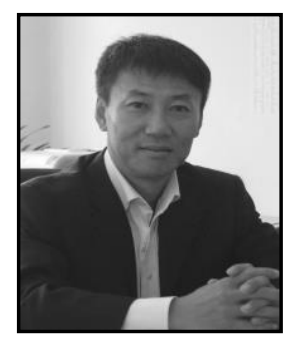

Xiao-dong Su is an professor of Harbin University of Commerce and he is the member of council of the China Software Industry Association, vice president of Electronics Experiment Teaching Research Council of Universities in Heilongjiang, member of Heilongjiang Computer Society Education and Training Professional Committee. His recent research interests are in information detection and estimation, management information systems. 